\title{
Correlação entre SARS-CoV-2 e o ebola
}

\author{
Correlation between SARS-CoV-2 and ebola \\ Correlación entre SARS-CoV-2 y ebola
}

Nágila Iane Pacheco

ORCID: https://orcid.org/0000-0002-2836-1639 Centro Universitário UNIFACID/ WYDEN, Brasil

E-mail: nagilaiane@hotmail.com

Luiza Aragão Paiva Pires Ferreira Mendes

ORCID: https://orcid.org/0000-0002-4017-6102 Centro Universitário UNIFACID/ WYDEN, Brasil

E-mail: luizamendes300@ hotmail.com

Gabriel de Sousa Carneiro

ORCID: https://orcid.org/0000-0002-0881-7870

Faculdade Maurício de Nassau, Brasil

E-mail: gabrieldesousa2735@gmail.com

Mariana Pacheco de Sousa

ORCID: https://orcid.org/0000-0001-8068-3347

Universidade Estadual de São Paulo, Brasil

E-mail: mp.sousa@unesp.br

Jucilene da Silva Sousa

ORCID: https://orcid.org/0000-0001-9692-3499

Centro Universitário UNIFACID/ WYDEN, Brasil

E-mail: sousajucilene9@gmail.com

Ian Carlos Cavalcante Vasconcelos

ORCID: https://orcid.org/0000-0002-7642-7284

Faculdade Maurício de Nassau, Brasil

E-mail: ianvasconcelos10@gmail.com

Bruna Ellen Ribeiro de Oliveira

ORCID: https://orcid.org/0000-0002-5728-5196

Faculdade Maurício de Nassau, Brasil

E-mail: brunasr588@gmail.com

Bruna da Silva Azevedo

ORCID: https://orcid.org/0000-0001-7816-9277

Centro Universitário UNIFACID/ WYDEN, Brasil

E-mail: brunasilva77200@hotmail.com

Isabelle Vasconcelos Rodrigues

ORCID: https://orcid.org/0000-0003-2280-1020

Universidade Federal do Piauí, Brasil

E-mail: isabellevasconcelosrodriguess@ hotimail.com

Adryana Ryta Ribeiro Sousa Lira

ORCID: https://orcid.org/0000-0002-1639-3369

Centro Universitário UNIFACID/ WYDEN, Brasil E-mail:dryribeiro22@gmail.com

Jorge Davi de Sousa e Silva

ORCID: https://orcid.org/0000-0003-3157-1108

Centro Universitário UNIFACID/ WYDEN, Brazil

E-mail: jddavisilva123@gmail.com

Fernando Henrique Lima Sa Machado

ORCID: https://orcid.org/0000-0001-5195-390X

Centro Universitário UNIFACID/ WYDEN, Brasil

E-mail: biomed.fernando.machado@gmail.com

Jordianne Thamires Rodrigues Bezerra

ORCID: https://orcid.org/0000-0003-3854-1024

Centro Universitário UNIFACID/ WYDEN, Brasil

E-mail: jordiannethamires@ hotmail.com

Veronildes de Sousa e Silva

ORCID: https://orcid.org/0000-0001-5038-1997

Centro Universitário UNIFACID/ WYDEN, Brasil

E-mail: veronildessilva123@gmail.com 


\begin{abstract}
Resumo
Introdução: A Organização Mundial de Saúde em 2020 declarou a pandemia do SARS-CoV-2, que apresenta alta transmissibilidade causando uma síndrome respiratória aguda fatal. Outrossim, uma doença rara e mortal, além do citado a cima, provada por um vírus é o do Ebola em primatas (incluído o homem), constituem como mais mortífero e disseminado nos surtos globais. Objetivo: estabelecer a comparação entre o coronavirus e o ebola com foco na mortalidade e letalidade. Metodologia: uma revisão integrativa da literatura, utilizando bancos de dados online como: BVS, SCIELO, PUBMED, MEDLINE, WHO, IDRC, MS, CDC. Resultado e Discussões: Em 2020, ocorreu o 10 surto de Ebola e a $2^{\circ}$ maior desde sua descoberta em 1976, notificou-se 3.470 casos. Atualmente em 2021, conforme a Semana Epidemiológica (SE) 43, em 30 de outubro, confirmou-se 246.407.251 casos de COVID-19 no mundo. Comparando o coronavírus, que possui sua letalidade de 6,1\% das pessoas eivadas, com a ameaça do Ebola vírus, abrangendo $90 \%$, considera-se mais agravante, por ocasionar rapidamente as mortes dos enfermos. Conclusão: Dessa forma, a COVID-19 e o Ebola são vírus de ameaças a saúde pública global, devido as suas elevadas taxas de morbidade e mortalidade. Contudo, carece seguir os protocolos e as recomendações da Organização Mundial da Saúde no controle e prevenção das enfermidades.
\end{abstract}

Palavras-chave: Letalidade; COVID-19; SARS-CoV-2; Ebolavirus.

\begin{abstract}
Introduction: The World Health Organization in 2020 declared the SARS-CoV-2 pandemic, which has high transmissibility causing a fatal acute respiratory syndrome. Furthermore, a rare and deadly disease, in addition to the above mentioned, proven by a virus is Ebola in primates (including man), which constitutes the most deadly and disseminated disease in global outbreaks. Objective: to establish a comparison between coronavirus and Ebola with a focus on mortality and lethality. Methodology: an integrative literature review using online databases such as: BVS, SCIELO, PUBMED, MEDLINE, WHO, IDRC, MS, CDC. Results and Discussions: In 2020, the 10th Ebola outbreak occurred and the 2nd largest since its discovery in 1976, 3,470 cases were reported. Currently, in 2021, according to Epidemiological Week (SE) 43, on October 30, 246,407,251 cases of COVID-19 have been confirmed in the world. Comparing the coronavirus, which has a fatality rate of $6.1 \%$ of infected people, with the threat of the Ebola virus, covering $90 \%$, it is considered more aggravating, as it quickly causes the deaths of the sick. Conclusion: Thus, COVID-19 and Ebola are viruses that threaten global public health, due to their high rates of morbidity and mortality. However, it is necessary to follow the protocols and recommendations of the World Health Organization in the control and prevention of diseases.
\end{abstract}

Keywords: Lethality; COVID-19; SARS-CoV-2; Ebolavirus.

\title{
Resumen
}

Introducción: La Organización Mundial de la Salud en 2020 declaró la pandemia del SARS-CoV-2, que tiene una alta transmisibilidad y causa un síndrome respiratorio agudo fatal. Además, una enfermedad rara y mortal, además de las mencionadas anteriormente, probada por un virus es el Ébola en primates (incluido el hombre), que constituye la enfermedad más mortal y diseminada en los brotes mundiales. Objetivo: establecer una comparación entre coronavirus y ébola con enfoque en mortalidad y letalidad. Metodología: revisión integradora de la literatura utilizando bases de datos en línea como: BVS, SCIELO, PUBMED, MEDLINE, OMS, IDRC, MS, CDC. Resultados y discusiones: En 2020, ocurrió el décimo brote de ébola y el segundo más grande desde su descubrimiento en 1976, se reportaron 3.470 casos. Actualmente, en 2021, según la Semana Epidemiológica (SE) 43, el 30 de octubre se han confirmado 246.407.251 casos de COVID-19 en el mundo. Comparando el coronavirus, que tiene una tasa de letalidad del 6,1\% de las personas infectadas, con la amenaza del virus del Ébola, que cubre el 90\%, se considera más agravante, ya que provoca rápidamente la muerte de los enfermos. Conclusión: Así, el COVID-19 y el Ébola son virus que amenazan la salud pública mundial, debido a sus altas tasas de morbilidad y mortalidad. Sin embargo, es necesario seguir los protocolos y recomendaciones de la Organización Mundial de la Salud en el control y prevención de enfermedades.

Palabras clave: Letalidad; COVID-19; SARS-CoV-2; Ebolavirus.

\section{Introdução}

Desde 1960, a comunidade científica está ciente das infecções por Coronavírus. Mediante as pesquisas, há sete tipos principais de Coronavírus Humano, quatro dos quais ocasionam 5-10\% das doenças respiratórias agudas leves. São eles: HCoV-OC43, HCoV-HKU1, HCoV-229E e HCoV-NL63. Os três outros tipos reconhecidos causam síndrome respiratória grave: MERS-CoV (Síndrome Respiratória do Oriente Médio), SARS-CoV e SARS-CoV-2 (Síndrome Respiratória Aguda Grave) (CHEN, 2020). O Coronavírus é zoonótico, de RNA da ordem Nidoviral, da família dos Coronavírus do gênero 
Betacoronavirus. Constitui-se em formato circular ou elíptico e apresenta alguns polimorfismos, com diâmetro de 60 a $140 \mathrm{~nm}$ (Lima, 2020; Calvo et al., 2020; Lai et al., 2020).

O SARS-CoV-2 é um vírus de RNA com fita simples, positiva e envelopada, que afeta negativamente o sistema respiratório, intestinal, hepático e nervoso dos animais e seres humanos. Antes da descoberta desses, identificaram-se apenas seis tipos. Entre eles, HCOV-229E, HCOV-NL63, HCOV-OC43 e HCOV-HKU1, acarretam infecções respiratórias autolimitadas, graves, principalmente, em bebês, pacientes imunossuprimidos e senis. A SARS e o MERS pertencem às subclasses B e C de $\beta$-coronavírus, respectivamente, ambos podem causar a doença respiratória fatal (Chen, 2020).

Os sintomas iniciais das infecções por MERS, SARS ou COVID-19 são inespecíficos. Encontram-se recorrentemente com sintomatologia de febre e tosse seca, outros sintomas comuns incluem mialgia, dispneia, dificuldade em respirar, calafrios e problemas gastrointestinais, como diarréia, náusea e vômito, são as primeiras sintomatologias em alguns enfermos. Contudo, majoritariamente, os pacientes evoluem para complicações potenciais, por exemplo, os casos graves evoluirão de hipoxemia para síndrome do desconforto respiratório agudo (SDRA) à falência de múltiplos órgãos ou até óbito (Chen et al., 2020).

A transmissão ocorre de indivíduo para indivíduo, confirmou-se na China e nos Estados Unidos (Brasil, 2020) e ocorre, principalmente, no contacto com gotículas respiratórias de pacientes sintomáticos (WHO, 2020). O tempo de incubação, em média é estimado em 5 a 6 dias, variando entre 0 a 14 dias (Razai, 2020).

Outrossim, uma doença rara e mortal, além do citado a cima, provada por um vírus é o do Ebola em primatas (incluindo o homem). Este causa a enfermidade do Ebola vírus (EVD), localizado principalmente na África Subsaariana. As pessoas obtêm através do contacto direto doentes, mortos ou animais eivados, dentre eles, os morcegos e os macacos. O Ebola concerne à família Filoviridae, suas seis espécies identificadas no gênero são: vírus Zaire, vírus BundyBuyo, vírus Sudão, vírus Floresta Tai, vírus Reston e vírus Bombay. Entre essas espécies, o Zaire ou Ebola vírus Zaire, constituem como mais mortífero e disseminado nos surtos globais. Posteriormente, as pessoas eivadas não demonstram uma sintomatologia imediata, o período entre a exposição aos sintomas é denominado período de incubação, somente é transmitido quando se demonstra sintomas (CDC, 2019).

Esse período, geralmente, está á volta de 2 a21 dias, dependendo do Filovírus, da dose e da via de exposição, conseguem variar de 6 à 10 dias. Inicialmente, a infecção manifesta-se como uma doença febril inespecífica caracterizada por desconforto, fadiga e mialgia. Em seguida, desenvolvem manifestações gastrointestinais, acompanhadas de anorexia, náusea, vômito e diarréia, promovendo perda de até 10 litros/dia de fluido. Além de disfagia, encefalite, injeção conjuntival, dor abdominal, artralgia e erupção cutânea maculopapular. Raramente, possuem anormalidades hemorrágicas, mas são correlacionadas como sangramento das gengivas, petéquias, exsudação dos locais de punção venosa, hemorragia subconjuntival e sangue no gorfo e nas fezes (Baseler, 2017; Nicastri, 2019).

O Ebola espalha-se, inicialmente, para as pessoas pelo contato indireto e direto, por tecidos de animais, objetos contaminados, falecidos e fluidos corporais (sangue e sêmen). Esses penetram nas úlceras ou pelas mucosas oral, nasal e ocular, mesmo após a recuperação, persistem no fluido (CDC, 2019). Esse trabalho justifica-se pela necessidade atual de conhecimentos que envolvam a COVID-19 e suas correlações, como no caso em questão, o Ebola. Apresenta como objetivo paragonar o Coronavirus e o Ebola em sua mortalidade e letalidade, por intermédio de uma revisão integrativa da literatura.

\section{Metodologia}

Trata-se de uma revisão integrativa da literatura (Paiano, 2020) estabelecendo a comparação entre o Coronavírus e o Ebola, utilizando bancos de dados online. Recuperou-se os artigos principais especialmente da Biblioteca Virtual de Saúde (BVS), Scientific Electronic Library Online (SCIELO), Science Direct e Medical Literature Analysis and Retrieval System 
Online (MEDLINE), PUBMED, Ministério da Saúde (MS), Centers For Disease Control and Prevention (CDC) e World Health Organization (WHO).

Os critérios de inclusão do referido levantamento deram-se através da utilizando os termos Lethality; COVID-19; SARS-CoV-2; Ebolavirus, utilizando-se o descritor booleano "AND”, que retratassem somente publicações com foco na mortalidade e letalidade. Ademais publicações científicas de 2017 a 2021, levantou-se 20 artigos da SCIELO, 97 artigos da BVS, inclusos a MEDLINE, PUBMED, 3 do MS, 1 do CDC, 1 do IDRC e 4 do WHO, como demonstra-se na Figura 1.

Nesse levantamento são relatados no total 20 artigos utilizados neste estudo, limitando-se os resultados em inglês, espanhol e português. Todas as pesquisas, como a triagem de títulos, resumos e a seleção de estudos executaram-se pelos pesquisadores que trabalharam de forma independente. Resolveu-se que quaisquer divergências por consenso. Todos os artigos considerados potencialmente elegíveis foram aplicados para revisão em texto completo. Limitou-se resultados de pesquisa a publicações em português, espanhol e inglês e excluímos artigos indisponíveis, artigos não publicados, resumos de conferências e comentários.

Figura 1: Esquema das etapas realizadas para seleção dos artigos.

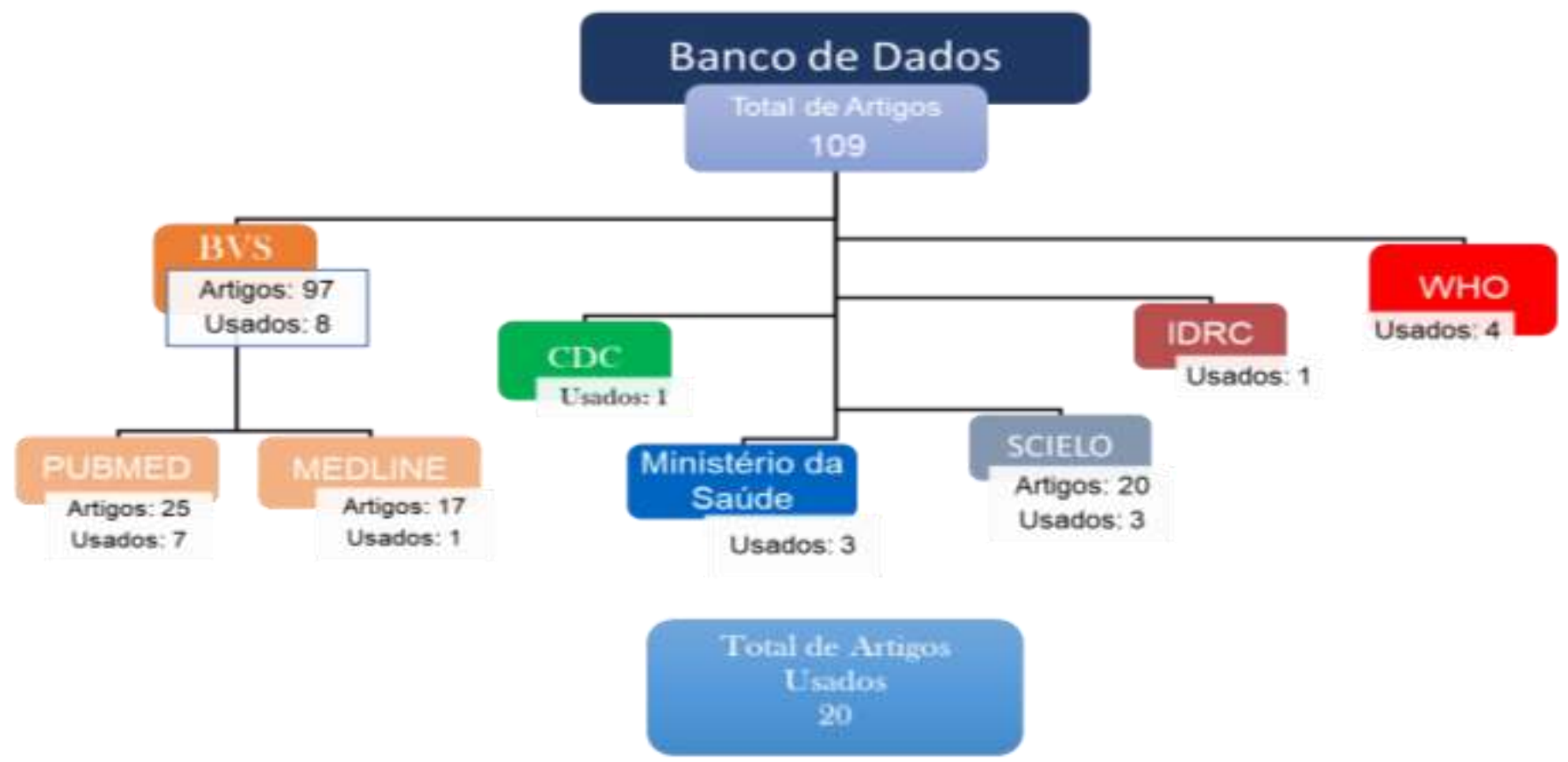

Fonte: Pacheco (2021).

\section{Resultados e Discussão}

Entre 2002 a 2004, na China, houve uma epidemia do SARS-COV que atingiu acima de 20 países e ocasionou 754 mortes (Peeri et al., 2020). Em 2012, na Arábia Saudita o MERS-CoV, obteve 27 países, causando 858 mortes (WHO, 2020). Embora esses dois patógenos tenham potencial para epidemias, é importante considerar que a gravidade clínica entre ambos é diversificada. O índice de mortalidade do SARS-COV, cerca de 10\%, no surto de MERS-CoV atinge 35\%, significando que $50 \%$ a $80 \%$ dos casos requerem assistência ventilatória (Chen et al., 2020; Peeri et al., 2020).

Em dezembro de 2019, em Wuhan na China, ocorreu a eclosão da epidemia de Coronavírus denominado SARS-CoV2, espalharam-se para outros continentes. Em 30 de janeiro de 2020, a Organização Mundial da Saúde (OMS) alegou que a epidemia COVID-19 constituía uma emergência de saúde pública de importância internacional (ESPII) (WHO, 2020), em 11 
de março de 2020, considerou uma pandemia. Esse anunciou uma emergência de saúde pública de importância nacional (ESPIN), em 3 de fevereiro de 2020 (Brasil, 2020). O SARS-CoV-2 apresenta alta transmissibilidade causando uma síndrome respiratória aguda, que varia entre casos leves, cerca de $80 \%$ e graves, entre $5 \%$ a $10 \%$ dos casos, sua letalidade diferencia, em concordância com a faixa etária e com as condições associadas (Brasil, 2020).

Atualmente em 2021, conforme a Semana Epidemiológica (SE) 43 de 2021, em 30 de outubro, confirmou-se 246.407.251 casos de COVID-19 no mundo. No Brasil, possui 21.804.094 casos, com 607.694 óbitos, aparecendo na 6 posição no coeficiente de mortalidade com 2.869,8 óbitos/1 milhão habitantes, investigou-se que apenas 7,8\% dos casos no país são notificados. Até a finalização da SE 43, pressupõe que 94,9\% (233.862.765/ 246.407.251) da população contaminada se recuperaram, e em $3^{a}$ posição encontra-se o Brasil com 20.992.510 ou 9\% (Prado, 2020; Brasil, 2021).

Comparando o Coronavírus, que possui sua letalidade 6,1\% das pessoas eivadas, com a ameaça do Ebola, abrangendo 90\%, considera-se mais agravante, por ocasionar rapidamente as mortes dos enfermos (Brasil, 2021; Brasil, 2019). No acareamento de ambos os vírus, desde a descoberta do Ebola, visualizado primeiramente na República Democrática do Congo (RDC) em 1976, encarregado em menos de 38 surtos registrados no mundo. No entanto, embora alguns sejam limitados, majoritariamente dos casos, ainda são generalizados (CDC, 2019).

Apesar disso, novos surtos atingiram proporções epidêmicas sem igual no final de 2013, que se espalhou amplamente entre 2014 a 2016 na África Ocidental, resultou em mais de 11.000 mortes registradas devido à rápida disseminação e abrangência dos diversos países. Na Libéria, no Guiné e Serra Leoa são os mais afetados, 28.600 casos confirmados em laboratório e, aproximadamente, 11.300 mortes em um curto período de tempo. Houve a perda econômica de aproximadamente US \$4,3 bilhões, onde tiveram um enorme impacto na vida e nos meios de subsistência dos residentes, tornando-se um surto complexo e abrangente, desde sua descoberta em 1976. Esses casos levaram a OMS a declarar uma ESPII em 2014, que finalizou-se em 2016, embora vários tenham sido registrados e atribuídos aos contágios posteriores (Brown et al., 2017; IDRC, 2019).

A RDC entre 1 de agosto de 2018 à 25 de junho de 2020, enfrentou o $10^{\circ}$ surto de Ebola e a $2^{\circ}$ maior desde sua descoberta em 1976, notificou-se 3.470 casos, existindo 3.317 casos confirmados e 153 prováveis, com 2.287 óbitos e 1.171 sobreviventes. Em 25 de junho de 2020, a OMS declarou o fim do surto pelo vírus Ebola nas províncias de Kivu do Norte, Ituri e Kuvi do Sul. A sua taxa média de mortalidade é cerca de $50 \%$ e os índices de mortalidade dos casos variam entre $25 \%$ à $90 \%$ nos anteriores (Quadro 1) (WHO, 2020).

Quadro 1: Cronologia dos Surtos do Vírus Ebola na África Subsaariana.

\begin{tabular}{|c|c|c|c|c|c|}
\hline Ano & País & EVD & Casos & Mortes & Fatalidade do caso \\
\hline $2014-2016$ & Serra Leoa & Zaire & $14124^{*}$ & $3956^{*}$ & $28 \%$ \\
\hline $2014-2016$ & Libéria & Zaire & $10675^{*}$ & $4809^{*}$ & $45 \%$ \\
\hline $2014-2016$ & Guiné & Zaire & $3811^{*}$ & $2543 *$ & $67 \%$ \\
\hline 2014 & Nigéria & Zaire & 20 & 8 & $40 \%$ \\
\hline 2014 & Mali & Zaire & 8 & 6 & $75 \%$ \\
\hline 2014 & Senegal & Zaire & 1 & 0 & $0 \%$ \\
\hline 2017 & RDC & Zaire & 8 & 4 & $50 \%$ \\
\hline 2018 & RDC & Zaire & 54 & 33 & $61 \%$ \\
\hline $2018-2020$ & RDC & Zaire & 3.481 & 5.299 & $66 \%$ \\
\hline 2020 & RDC & Zaire & 130 & & $42 \%$ \\
\hline 2021 & RDC & Zaire & Em andamento & & \\
\hline 2021 & Guiné & Zaire & Em andamento & & \\
\hline
\end{tabular}

* Inclui casos suspeitos, prováveis e confirmados de EVD. Fonte: WHO (2020). 
O Ministério da Saúde da RDC anunciou o $11^{\circ}$ surto da patologia pelo Ebola vírus em $1^{\circ}$ de junho de 2020 , em seguida, detectou-se um encadeamento de casos na região de Mbandaka, localizada na província de Equateur. A análise da sequência genética pelo Instituto Nacional de Pesquisa Biomédica (INRB) da RDC descobriu-se o novo vírus que circula no oeste, é diversificado do que eivou mais de 3.400 pessoas no leste do país (WHO, 2020).

A análise de sequenciamento genético descobriu que o agente é completamente diferente do anterior que atingiu a mesma área em 2018. Estão em andamento investigações para determinar a nova fonte, porém é provável que tenha se originado por animais. No entanto, em $1^{\circ}$ de junho de 2020, a RDC anunciou uma nova onda de propagação, e 4 dos 6 pacientes inicialmente diagnosticados evoluíram para óbito (WHO, 2020).

Contudo, em 2021 declararam o $12^{\circ}$ surto do EVB encerrado, correlacionado ao ocorrido nas provincias de Kivu do Norte e Ituri de 2018-2020, contendo 11 casos confirmados e 1 provável, 6 recuperações e 6 mortes registradas, desde 7 de fevereiro nas quatros zonas de saúde. Na Guiné, iniciou em 14 de fevereiro de 2021, ocasionando 12 mortos, das 23 infecções registadas, o ultimo enfermo confirmado com Ébola obteve alta médica em 24 de abril. A mesma não havia sido contaminada pelo Ébola, desde a enorme epidemia que atingiua África Ocidental, entre 2014 a 2016 (WHO, 2021).

\section{Conclusão}

Dessa forma, a COVID-19 e o Ebola são vírus de ameaças a saúde pública global, devido as suas elevadas taxas de morbidade e de mortalidade. Contudo, carece seguir os protocolos e as recomendações da Organização Mundial da Saúde para o controle e prevenção das enfermidades. Ambos, os modos de precaver correspondem em frequentemente higienizar as mãos, evitando objetos contaminados, áreas de surto, o contacto com outras pessoas, fluidos corporais, contatos com os falecidos e uso obrigatório de máscara. Informatizando as comunidades da propagação, da transmissão e dos cuidados para o controle do vírus. É necessário ainda um maior investimento em pesquisas em longo prazo da mortalidade e letalidade do COVID-19 e do Ebola, os dados obtidos nessa pesquisa podem fornecer base para novas pesquisas.

\section{Referências}

Baseler, L. \& Chertow, D.S. \& Johnson, K.M. \& Feldmann, H. \& Morens, D.M. (2017). The Pathogenesis of Ebola Virus Disease. Annual Review of Pathology: Mechanisms of Disease. 24;12:387-418. 10.1146/annurev-pathol-052016-100506.

Brasil. (2019). Ebola: causas, sintomas, diagnóstico, tratamento e prevenção. https://antigo.saude.gov.br/saude-de-a-z/ebola

Brasil. (2020). Secretaria de Atenção Primária à Saúde (SAPS). Protocolo De Manejo Clínico Do Coronavírus (Covid-19) Na Atenção Primária À SaúdeVersão 9. Recuperado de: http://docs.bvsalud.org/biblioref/2020/05/1095920/20200504-protocolomanejo-ver09.pdf

Brasil. (2021). Ministério da Saúde. Secretaria de Políticas de Saúde. Semana Epidemiológica 43 (24/10 a 30/10/2021). https://www.gov.br/saude/ptbr/media/pdf/2021/novembro/10/boletim_epidemiologico_covid_87_10nov21-substituir.pdf

Brown, C.S. \& Mepham, S. \& ShorteN, R.J. (2017). Ebola Virus Disease: An Update on Epidemiology, Symptoms, Laboratory Findings, Diagnostic Issues, and Infection Preventionand Control Issues for Laboratory Professionals. Clinics in laboratory medicine. un;37(2):269-284. 10.1016/j.cll.2017.01.003.

Calvo, C. \& López-hortelano, M. G. \& Vicente, J. \& Martínez, J.L.V. (2020). Recommendations on the clinical management of the COVID-19 infection by the «new coronavirus» SARS-CoV2. Spanish Paediatric Association working group. Anales de pediatria,92(4), 241.e1-241.e11. 10.1016/j.anpede.2020.02.002

Centers for disease control and prevention. (2019). National center for emerging and zoonotic infectious diseases. https://www.cdc.gov/vhf/ebola/index.html

Chen, Y. \& Liu, Q. \& Guo, D. (2020). Emerging coronaviruses: Genome structure, replication, and pathogenesis. Journal of Medical Virology Apr; 92(4): 418-423. 10.1002/jmv.25681

International development research center (IDRC). (2019). O Papel dos Fatores Sociais, Culturais e Ambientais na Melhoria da Resiliência e Resposta à Doença do Vírus Ebola. https://www.idrc.ca/en/project/role-social-cultural-and-environmental-factors-improving-ebola-virus-disease-response-and. 
Research, Society and Development, v. 10, n. 16, e294101623772, 2021

(CC BY 4.0) | ISSN 2525-3409 | DOI: http://dx.doi.org/10.33448/rsd-v10i16.23772

Lai, C. C. \& Shih, T.P. \& ko W. C. \& Tang, H.J.\& Hsueh, P.R. (2019). Severe acute respiratory syndrome coronavirus 2 (SARS-CoV-2) and coronavirus disease-2019 (COVID-19): The epidemic and the challenges. International jornal of antimicrobial agents. $2020 ; 105924(3): 55$. 10.1016/j.ijantimicag.2020.105924

Lima, C. (2020). Information about the new coronavírus disease (COVID-19). Radiologia Brasileira. 53(2), V-VI. 10.1590/0100-3984.2020.53.2e1

Nicastri, E. \& Kobinger, G. \& Vairo, F. \& Montaldo, C. \& Mboera, L.E. G. \& Ansunama, R. \& Zumla, A. \& Ippolito, G. (2019). Ebola Virus Disease: Epidemiology, Clinical Features, Managementand Prevention. Infectious Disease Clinicsof North America 33(4):953-976. 10.1016/j.idc.2019.08.005. PMID: 31668200.

Paiano, M. et al. (2020). Mental health of healthcare professionals in China during the new coronavirus pandemic: an integrative review. Revista Brasileira de Enfermagem. 73(2), e20200338. https://doi.org/10.1590/0034-7167-2020-0338

Peeri, N. C. \& Shrestha, N. \& Rahman, S. \& Zaki, R. \& Tan Z. \& Bibi S.\& Baghbanzadeh, M.\& Aghamohammadi, N. \& Zhang, W. \& Haque, U. (2020). The SARS, MERS and novel coronavirus (COVID-19) epidemics, thenewestand biggest global healththreats: what lessons have we learned? International Journal of Epidemiology 49(3):717-726. 10.1093/ije/dyaa033.

Prado, M. F. et al. (2020). Análise da subnotificação de COVID-19 no Brasil. Revista Brasileira de Terapia Intensiva. 32(2), 224-228. 10.5935/0103507X.20200030.

Razai, M. S., Doerholt, K., Ladhani, S., \& Oakeshott, P. (2020). Coronavirus disease 2019 (COVID-19): a guide for UK GPs. British medical journal (Clinical research ed.), 368, https://doi.org/10.1136/bmj.m800

Who. (2020). Novo surto de Ebola detectado no noroeste da República Democrática do Congo; Equipe de emergência da OMS apoiando a resposta. https://www.who.int/news/item/01-06-2020-new-ebola-outbreak-detected-in-northwest-democratic-republic-of-the-congo-who-surge-team-supporting-theresponse.

Who. (2020). Ebola: Kivu / Ituri do Norte, República Democrática do Congo, https://www.who.int/emergencies/situations/Ebola-2019-drc-.

Who. (2021). Doença pelo vírus Ebola. https://www.who.int/news-room/fact-sheets/detail/ebola-virus-disease.

Who. (2021). O Diretor Geral da OMS felicita a República Democrática do Congo quando o $12^{\circ}$ surto de Ebola é declarado encerrado; estresses precisam manter vigilância para evitar o retorno do vírus. https://www.who.int/news/item/03-05-2021-who-director-general-congratulates-the-democratic-republic-ofthe-congo-as-12th-ebola-outbreak-is-declared-over-stresses-need-to-maintain-vigilance-to-prevent-virus-s-return. 